\title{
Seasons of the Year via Art
}

\author{
Abraham Tamir* \\ Chemical Engineering Department, Ben-Gurion University of the Negev, Israel
}

Submission: November 14, 2017; Published: November 27, 2017

*Corresponding author: Abraham Tamir, Chemical Engineering Department, Ben-Gurion University of the Negev, Israel, Tel: 75689942663, Email: atamir4@012.net.il

\section{Short Communication}

Seasons are several major periods, winter, summer, spring and fall that divided the year on the planet. Each season of the year is characterized by a unique climate and a different number of hours of light a day. In general you can talk also about the seasons on other planets. There are three reasons for the seasonality and the seasons. The first is the rotation of the earth on its axis for 24 hours causes the exchange of day and night. The second reason is the rotation of the earth around the sun in an ellipse, one round for 365 days. As a result of this movement different parts of the earth are facing the sun and getting strong sunlight where once the strong radiation comes from the northern hemisphere and once from the southern hemisphere. The third reason is the tendency of the Earth on its side towards the sun at an angle of 23.5 degrees. Scientific background of the seasons is astronomy of natural sciences using observation and analyzing the traffic, the structure, formation and evolution of celestial bodies and the universe.

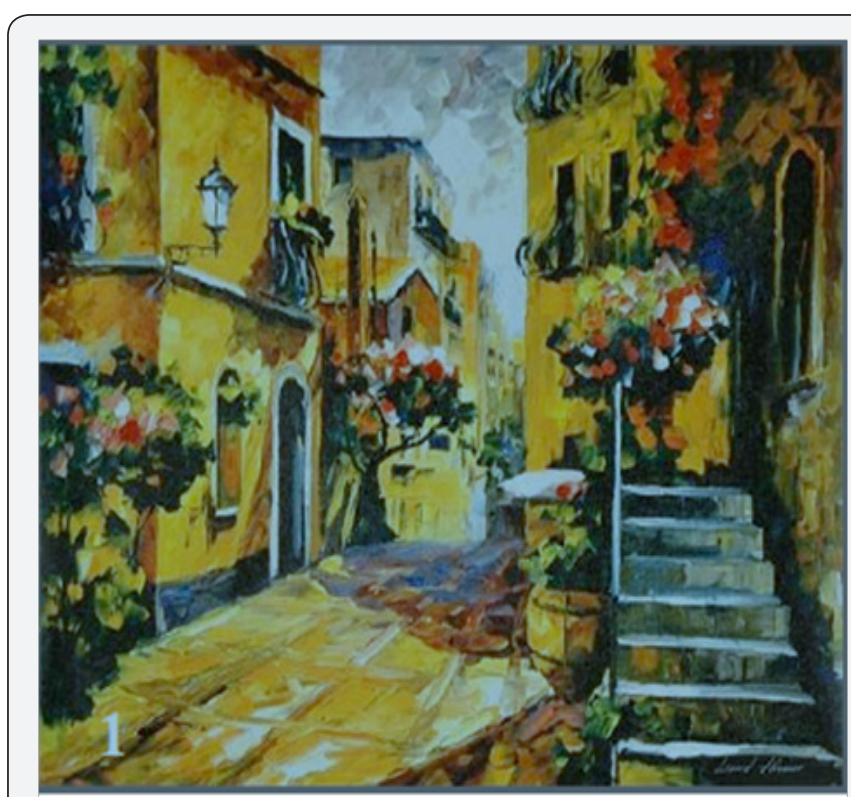

Figure 1
A unique feature of astronomy is that unlike other sciences, astronomy almost does not deal with experiments but deals with observations and is probably the oldest science. Primitive cultures which have been absent significant signs of modernity noticed basic astronomical phenomena such as sunrise and sunset, the sun tracks tendency seasons and their effect on the length of day and night and the weather. In the following we discuss the four seasons and describe each one by a work of art. Let's start by the summer that is the hottest season that followed the spring and is before the fall season. According to the astronomical definition summer begins during the summer solstice which is the longest day of the year, and hence the shortest night a year, and ends when day length is equal to the night length. Figure 1, «summer», describing this season is the work of the impressionist artist Leonid Efremov who was born in 1955 in Vitebsk, Belarus. The transition between summer and winter is the season of autumn and thus called transition season. Fall begins when the length of day is equal to the length of the night,

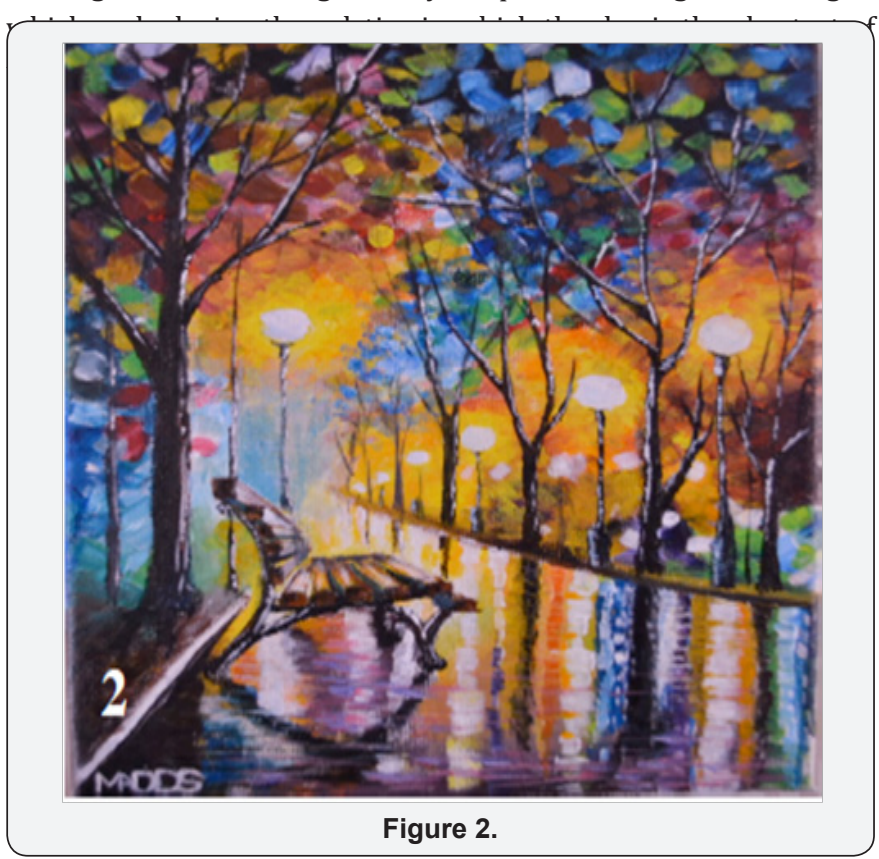




\section{Global Journal of Otolaryngology}

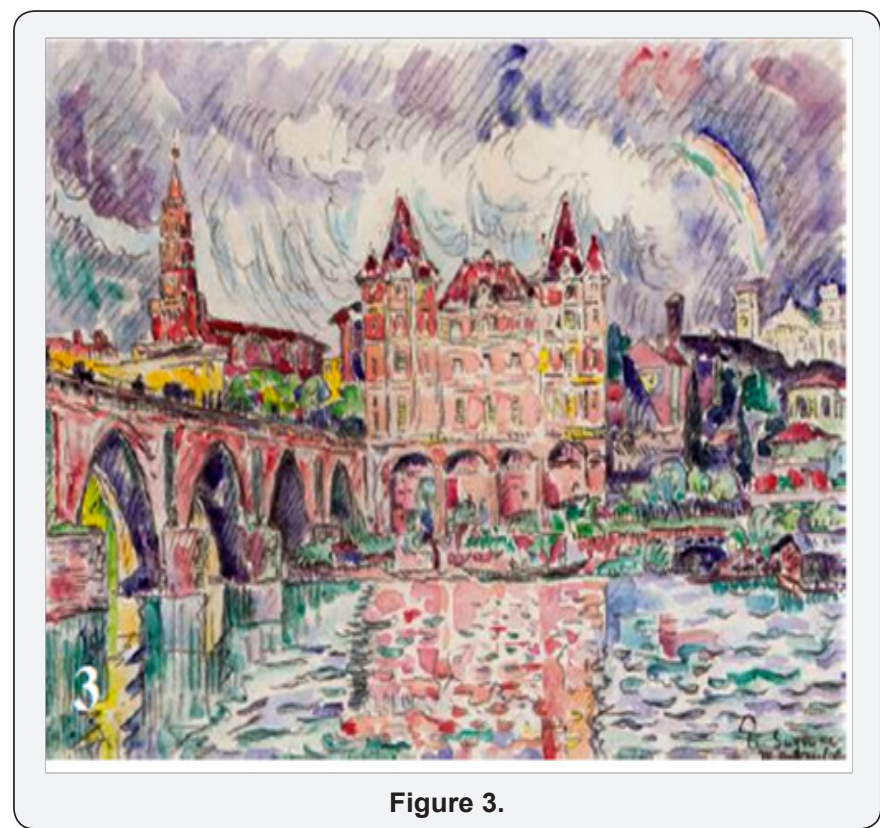

Israel Autumn is the season when the first rains fall. Autumn is demonstrated by Figure 2, «autumn», also the work of Leonid Efremov. Next season is the winter season in which days are shortest and temperatures are the lowest. Figure 3, «winter», is the work of French artist Neo-Impressionist Paul Signac (1935-1863). And finally the spring period that indicates the transition between winter and summer. Spring begins when day length is equal to night length and ends when day becomes the longest of the year and night is the shortest of the year. Figure 4, «spring», is the work of the artist Thomas Hart Benton, born in Missouri (1889-1975). In conclusion it should be noted that we are lucky of the changing seasons that makes human life in the universe more diversified and interesting.

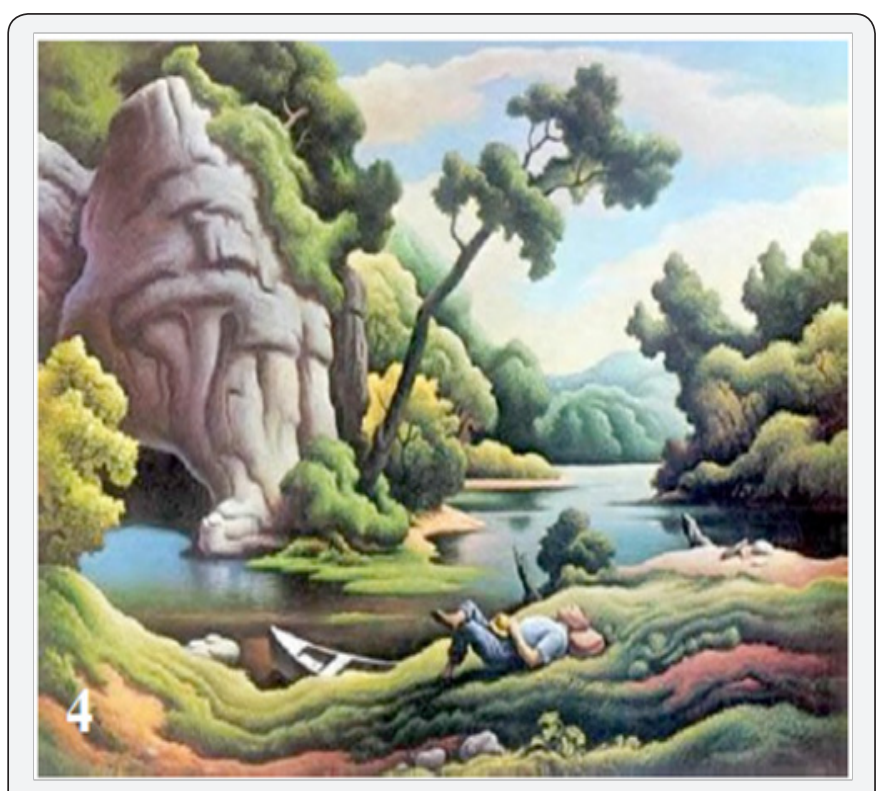

Figure 4.

\section{Your next submission with Juniper Publishers} will reach you the below assets

- Quality Editorial service

- Swift Peer Review

- Reprints availability

- E-prints Service

- Manuscript Podcast for convenient understanding

- Global attainment for your research

- Manuscript accessibility in different formats ( Pdf, E-pub, Full Text, Audio)

- Unceasing customer service

Track the below URL for one-step submission https://juniperpublishers.com/online-submission.php 